from neighbouring plants were collected. When samarium is bombarded with neutrons it is converted into europium, ${ }^{153} \mathrm{Eu}$, which emits gamma rays which can be counted. In this way, samarium-containing pollen can be located accurately. The results obtained obey the characteristic leptokurtic distribution, and show that very little pollen of either species tested is carried beyond $1 \mathrm{~m}$, although the species with the taller culm $(20 \mathrm{~cm}$ as opposed to $12 \mathrm{~cm}$ ) does have better powers of dispersal. The very small distance travelled by the pollen of these understorey herbs confirms what has been assumed about pollen movement beneath tree canopies. It also suggests that there must be a limited flow of genetic material between isolated individuals or populations of such species in woodlands, even if they produce copious pollen, depend upon wind pollination and have a tall culm.

The technique of neutron activation analysis in pollen studies offers considerable opportunities. The field is now open for the study of pollen movement from canopy species, the precise influence on dispersal of impaction on tree trunks, pollen dispersal from clearings and woodland edges and also the movement of pollen in insect-pollinated species. The technique, given the basic equipment, is fast and accurate and lacks the environmental hazards associated with radioactive labels. We can now await a flow of new data which will be of value to geneticist and palaeoecologist alike.

\title{
Hominid remains from Hadar, Ethiopia
}

\section{from our Palaeoanthropology Correspondent}

Although fossil-bearing deposits in the Hadar region of eastern Ethiopia have been explored only since 1973 it is already clear that this area is of extraordinary importance. As two recent papers indicate (Nature, 260, 289, 293; 1976), extremely favourable depositional conditions have allowed the preservation of many fossil specimens, even crocodile and turtle eggs, in a virtually complete state. This is an almost unique situation for PlioPleistocene deposits in Africa. Moreover, appropriate geological materials are available for chronometric dating of the sequences and although the absolute dates obtained so far are not entirely satisfactory, this problem should soon be resolved. Available information indicates that the hominid sites in the Hadar area are between 2 and 4 million years.

As reported in last week's issue, fossil material from approximately 17 hominids has been recovered from sites in the Hadar region. Of these, one of the most significant is AL 288, a partial skeleton recovered from the younger levels of the sequence. The partial skeleton is of a very small hominid which bears many similarities to the australopithecines from Sterkfontein, in South Africa. Certainly one of the most interesting aspects of this individual, from information available so far, is the direct indication of limb proportions in this early Pleistocene hominid. Estimates of upper and lower limb proportions have been made previously but never on virtually complete bones from a single individual. The ratio of humeral/femoral length in AL 288 is 83.9 ; living Homo sapiens has a mean of approximately 73 . By comparison, among the living great apes $P$ an $=102$, Gorilla $=116$, Hylobates $=113$ and Pongo $=135$. (Schultz, Hum. Biol., 9, 1937). Thus, although the length ratio of $\mathrm{AL} 288$ is somewhat above the human mean it is distinctly lower than that for the living great apes. Such a relationship has been expected, especially in view of the long humerus from East Rudolf (Leakey, Mungai and Walker, Am. J. Phys. Anthrop., 36, 1972) and the long ulna from the Omo River area just to the west of Hadar (Howell and Wood, Nature, 249, 174; 1974). These data clearly indicate the essential man-like body conformation of AL 288. This is of particular interest in view of Oxnard's recent claim (Nature, 258, $389 ; 1975)$ of the orang-like morphology of the australopithecines. This new information on limb proportions, along with the clear evidence of erect bipedality in the morphology of the pelvis, femur and knee joint does not lend support to such an assertion. Moreover, it indicates that computeroriented analyses on single bones, however sophisticated the statistics, may be of somewhat limited value in determin- ing morphological and functional affinities of fossil material. This is especially true when, as Oxnard recognised, the functional pattern of the fossil specimen may have no modern parallel.

Of additional interest in these papers is the report of two palates (AL 199 and AL 200) which Johanson and Taieb claim resemble other material referred to as Homo erectus. This material is from the lowest stratigraphic unit known to date in the Hadar region; if the data on the Kadada Moumou basalt is confirmed then this material would pre-date 3 million years. This possible early occurrence of Homo erectus is of particular interest since the redating of the KBS tuff in the East Rudolf area (Curtis et al., Nature, 258, $395 ; 1975$ ) would suggest that the early members of the genus Homo in that area are little more than 2 myr old.

Results of field work in the past few years have made it clear that at least two forms of hominid co-existed in east and possibly South Africa in PlioPleistocene times: one, a less advanced form usually called Australopithecus (or Paranthropus) and a more advanced form, Homo. This picture has achieved additional confirmation from the new material recovered at Hadar. The complexity of the fossil evidence at East Rudolf has led Richard Leakey to suggest a possible total of four hominid lineages there (Nature, 248, 653; 1974) and Johanson and Taieb, in the present paper, suggest possibly three at Hadar. Whatever the total number of contemporaneous hominid taxa in this area, it is clear that we are not seeing a simple and orderly progression of ancestor-descendant populations. The most economical interpretation of this diversity is that the early hominid line, once it had come to occupy the forestmargin/savannah ecozones, experienced a number of radiations and adaptations to this habitat. Such adaptive radiations are common during the initial occupation of a new habitat zone and serve to fit the immigrant populations to the available new niches. The molecular evolutionists, who have postulated a relatively recent origin for the family Hominidae, have made palaeontologists somewhat reluctant to talk about a great time depth for the hominids. But that is exactly what this PlioPleistocene diversity indicates. Such diversity, with two or more lineages, clearly suggests considerable antiquity for the human line, with splits having occurred in different places, at different times and in response to different environmental situations. Perhaps the appropriate question, however, in the face of such apparent diversity is not how many hominid lineages have existed but how many hominid econiches are available in such a habitat? 